\title{
Refractory Central Nervous System Non- Hodgkin Lymphoma
}

National Cancer Institute

\section{Source}

National Cancer Institute. Refractory Central Nervous System Non-Hodgkin Lymphoma. NCl Thesaurus. Code C146989.

A central nervous system non-Hodg kin lymphoma which does not respond to treatment. 